Research Paper

International Journal of Biological Sciences

ISSN 1449-2288 www.biolsci.org 2008 4(6):379-386

(C) Ivyspring International Publisher. All rights reserved

\title{
Production \& Characterization of a Unique Dextran from an Indigenous Leuconostoc mesenteroides CMG713
}

\section{Farwa Sarwat ${ }^{1}$, Shah Ali UI Qader ${ }^{2}{ }^{\boxplus}$, Afsheen Aman ${ }^{3}$ and Nuzhat Ahmed ${ }^{1}$}

1. Centre for Molecular Genetics, University of Karachi, Pakistan

2. Institute of Sustainable Halophytes Utilization, University of Karachi-75270, Pakistan

3. Pharmaceutical Research Centre, PCSIR Laboratories complex, Karachi, Pakistan

$\triangle$ Correspondence to: Dr. SHAH ALI UL QADER, Institute of Sustainable Halophyte Utilization, University of Karachi, Pakistan. Phone: ++ 92-21-4966045 Fax: ++ 92-21-4966045 E.mail: madar_chem@yahoo.com

Received: 2008.06.16; Accepted: 2008.07.14; Published: 2008.10.15

On the basis of high enzyme activity a newly isolated strain of L. mesenteroides CMG713 was selected for dextran production. For maximum yield of dextran, effects of various parameters such as $\mathrm{pH}$, temperature, sucrose concentration and incubation period were studied. L. mesenteroides CMG713 produced maximum dextran after 20 hours of incubation at $30^{\circ} \mathrm{C}$ with $15 \%$ sucrose at $\mathrm{pH} 7.0$. The molecular mass distribution of dextran produced by this strain showed that its molecular mass was about 2.0 million Da. Dextran analysis by ${ }^{13} \mathrm{C}-\mathrm{NMR}$ spectrometry showed no signals corresponding to any other linkages except $\alpha-(1 \rightarrow 6)$ glycosidic linkage in the main chain, which has not been reported before. Physico-chemical properties of this unique dextran were also studied. These optimised conditions could be used for the commercial production of this unique high molecular weight dextran, which have significant industrial perspectives.

Key words: L. mesenteroides, Dextran, NMR

\section{Introduction}

Dextran is an extracellular bacterial polymer of D-glucopyranose with predominantly a- $(1 \rightarrow 6)$ linkage in the main chain and a variable amount of $\alpha-(1 \rightarrow 2), a-(1 \rightarrow 3), \alpha-(1 \rightarrow 4)$ branched linkages [1-3]. Other workers have also reported formation of dextran from different strains of bacteria that were primarily Leuconostoc strains. The specificity of the synthesized linkages in the dextran is strain dependent. Among many dextran producing species the dextran produced by L. mesenteroides NRRL B512F and L. mesenteroides NRRL B1299 have been well characterized and classified. Dextran from L. mesenteroides B512F contains 95\% of $a-(1 \rightarrow 6)$ linkages and $5 \%$ of $a-(1 \rightarrow 3)$ branch linkages; whereas insoluble dextran from $L$. mesenteroides 1299 contains $63 \%$ a- $(1 \rightarrow 6), 27 \%$ of $a-(1 \rightarrow 2)$ and $8 \%$ of $\mathrm{a}-(1 \rightarrow 3)$ linkages [4].

Dextran is a bacterial polysaccharide, which is commercially available, and it is used as drugs, especially as blood plasma volume expander. Dextran has found industrial applications in food, pharmaceutical and chemical industries as adjuvant, emulsifier, carrier and stabilizer [5]. Cross-linked dextran is known as Sephadex, which is widely used for the separation and purification of protein. In food industry dextran is currently used as thickener for jam and ice cream [6]. It prevents crystallization of sugar, improves moisture retention, and maintains flavour and appearance of various food items $[7,8,9]$.

Dextran is produced at the industrial level by the fermentation of sucrose-rich media. Several research workers have optimized fermentation conditions for maximum dextran production. It has been reported earlier that molecular weight and yield of dextran production depends on the process variables such as temperature, sucrose and the acceptor concentration $[10,11]$. It was also mentioned that medium containing nitrogen source supplemented with different salts increased dextran production.

The present study was aimed to establish optimum conditions for maximum production of dextran, the molecular mass of the product and to analyse the structure of dextran from L. mesenteroides CMG713. In addition physico-chemical properties of this unique dextran were also studied.

\section{Materials \& methods}

Isolation of Leuconostoc strain 
Bacterial culture CMG713 was isolated from Vitis vinifera L. (Grape) purchased from local market using enrichment media technique. Sample was inoculated in a broth medium containing: $\left(\mathrm{g} \mathrm{l}^{-1}\right)$ : sucrose, 50.0; tryptone, 10.0; yeast extract, 1.0; $\mathrm{K}_{2} \mathrm{HPO}_{4}$, 2.5; the $\mathrm{pH}$ was adjusted at 7.0 and autoclaved at $121^{\circ} \mathrm{C}$ for 15 minutes. After autoclaving, $0.005 \%$ sodium azide was added aseptically to the medium for selective isolation of dextran producing Leuconostocs sp. Inoculated broth was incubated for $24 \mathrm{hrs}$ at $25^{\circ} \mathrm{C}$ and streaked on the agar plates containing the above medium to isolate pure culture [12]. Colonies showing highly viscous slimy growth on sucrose agar plate were selected (Fig.1).

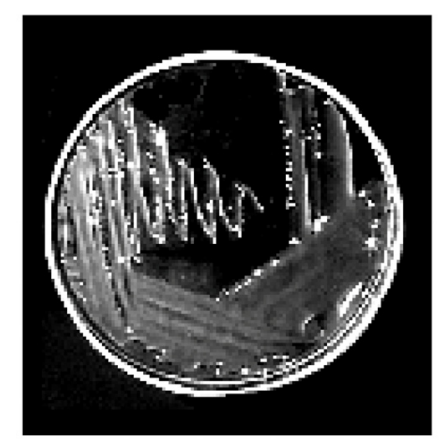

Figure 1: Slimy shiny growth of dextran producing Leuconostoc mesenteroides CMG713 on sucrose containing medium with $0.005 \%$ sodium azide.

\section{Strain selection and identification}

L. mesenteroides CMG713 was selected for this study due to its highest activity of dextransucrase and dextran producing characteristic. Bacterial strain CMG713 was identified according to the Bergey's Manual of Determinative Bacteriology [13] and confirmed by 16s rRNA gene sequencing analysis using universal primers [14].

\section{Medium composition}

For dextran production, the culture was grown in the medium containing (g l $\left.\mathrm{l}^{-1}\right)$ : sucrose, 150.0; bacto-peptone, 5.0; yeast extract, 5.0; $\mathrm{K}_{2} \mathrm{HPO}_{4}$, 15.0; $\mathrm{MnCl}_{2} . \mathrm{H}_{2} \mathrm{O}, 0.01 ; \mathrm{NaCl}, 0.01 ; \mathrm{CaCl}_{2}, 0.05$. For enzyme production, $20.0 \mathrm{~g} \mathrm{l}^{-1}$ sucrose was used whereas rest of the medium composition was same as above and $\mathrm{pH}$ was adjusted to 7.0 before sterilization at $121^{\circ} \mathrm{C}$ for 15 minutes.

\section{Cultivation conditions}

For all optimization studies, $10.0 \mathrm{ml}$ of overnight culture were inoculated in $90 \mathrm{ml}$ of fresh broth and incubated at $30^{\circ} \mathrm{C}$ for 24 hours. This $100 \mathrm{ml}$ fermented broth was used for dextran production.

\section{Time Course for dextransucrase and dextran pro- duction}

To study the effect of time on dextran production, culture media were incubated for different time intervals (0-48 hours). Dextran production, dextransucrase activity, total protein, final $\mathrm{pH}$ of fermented culture broth and wet cell mass are determined.

\section{Effect of substrate concentration, temperature and pH on dextran production}

Substrate concentration was varied from 10 to $20 \%$ in the culture media and all the flasks were incubated at $30^{\circ} \mathrm{C}$ for 20 hours. Effect of temperature was studied in the temperature range of 20 to $45^{\circ} \mathrm{C}$ with an increment of $5^{\circ} \mathrm{C}$. For temperature optimization $100 \mathrm{ml}$ of fresh broths containing 15\% sucrose was used. $\mathrm{pH}$ of the cultivation media were adjusted from 6.0 to 8.0 with an increment of 0.5 before sterilization and the cultivation media were incubated at $30^{\circ} \mathrm{C}$ for 20 hours.

\section{Dextran production}

Growing culture of L. mesenteroides CMG713 was incubated at $30^{\circ} \mathrm{C}$ for 24 hours in $10 \mathrm{ml}$ broth medium and after 24 hours it was transferred into $100 \mathrm{ml}$ sterile broth and again incubated at $30^{\circ} \mathrm{C}$ for 24 hours which served as inoculum. After 24 hours incubation $100 \mathrm{ml}$ inoculum was transferred into $900 \mathrm{ml}$ sterile broth and again incubated at $30^{\circ} \mathrm{C}$ for 20 hours for dextran production.

\section{Precipitation of dextran}

The culture medium after 20 hours was precipitated using equal volume of chilled ethanol, shaken vigorously, centrifuged at 10,000 rpm for 15 minutes and the supernatant was decanted. This step was repeated twice. The precipitated dextran was dried under vacuum over calcium chloride at $30^{\circ} \mathrm{C}$. The dextran yield was calculated on dry weight basis.

\section{Purification of dextran}

For removal of impurities dextran obtained from precipitation was dissolved in distilled water. The dextran slurry was again precipitated with equal volume of chilled ethanol. This procedure of re-dissolving, precipitation and washing was repeated thrice to remove cells debris. Purified dextran was dried under vacuum over calcium chloride at $30^{\circ} \mathrm{C}[15$, 16].

\section{Determination of viscosity}

Dextran solution (5\%) was used as a stock solution for viscosity measurement at $25^{\circ} \mathrm{C}$ using an Ostwald Viscometer [17].

\section{Enzyme assay}

Dextransucrase activity was determined by measuring the reducing sugar released from sucrose [18]. Units of dextransucrase activity are represented 
in DSU/ml/hr. "One unit of enzyme activity was defined as the enzyme quantity that converts 1.0 milligram of sucrose into fructose and dextran in 1.0 hour under standard conditions" [19].

\section{Estimation of total protein, total sugar and reducing sugar}

Total protein was determined by the Lowry's method using bovine serum albumin as a standard [20]. Total sugar was determined by Anthrone method using sucrose as a standard [21]. Reducing sugar was determined by Nelson-Somogyi's method [22, 23].

\section{${ }^{13} \mathrm{C}$-NMR spectroscopic analysis}

The ${ }^{13} \mathrm{C}$-NMR spectra of the dextran was recorded as reported earlier [24] with a Bruker AC 400 spectrometer operating at a frequency of $100.624 \mathrm{MHz}$. Samples were examined as solutions in $\mathrm{D}_{2} \mathrm{O}$ at $25^{\circ} \mathrm{C}$ in 5-mm diameter spinning tubes. The chemical shift values are reported in ppm $(\delta)$. Various signals were assigned as described by Seymour et al. [25] and Remound et al. [26].

\section{Determination of average molecular weight of dex- tran}

The average molecular mass of dextran isolated from L. mesenteroides CMG713 was determined by gel permeation chromatography using Sepharose CL6B (Sigma). LKB gel filtration system was used for this purpose. Blue dextran 2000 (Sigma, Average Mol. wt. 200,000) and Industrial dextran (Sigma, Average Mol. wt. 5,000,000-40,000,000) were used as standards. The sample was applied through automatic sample applicator on XK16/70 glass column packed with Sepharose CL6B. It was eluted with $0.1 \mathrm{M}$ citrate phosphate buffer (pH 5.0) at a constant flow rate of $20 \mathrm{ml} / \mathrm{hr}$. The fractions (40 drops/ Fr.) were collected through automatic fraction collector Ultro Rac II (Model LKB 2070).

\section{Results and discussion}

\section{Identification of the Organism}

Taxonomic assessment of the isolated strain confirmed the characteristic properties of L. mesenteroides and the strain CMG713 was identified as a member of genus L. mesenteroides by 16s rRNA gene analysis [27] (GenBank Accession \# DQ208970).

\section{Effect of Various Parameters on Dextran Produc- tion}

\section{Time Course for the Production of Dextransucrase \& Dextran}

Dextran of high molecular weight is being produced by a bacterium L. mesenteroides CMG713. Results have suggested that the enzyme activity and dextran production are function of time. Dextran production and enzyme activity by L. mesenteroides CMG713 with reference to time is shown in Table 1 . Maximum enzyme activity was observed at 20 hours of incubation, it was $40 \mathrm{DSU} / \mathrm{ml} / \mathrm{hr}$ (Fig. 2). The initial wet cell mass increased from $0.21 \mathrm{~g} / \mathrm{dl}$ up to $2.4 \mathrm{~g} / \mathrm{dl}$ at 20 hours and then entered the decline phase. The enzyme activity correlates well with the bacterial growth of L. mesenteroides CMG713. The production of the dextran and the enzyme activity increased with time and after reaching maxima at 20 hours, dextran production decreased along with a significant decrease in enzyme activity (Fig. 2). The $\mathrm{pH}$ of the fermented broth also decreased from the initial $\mathrm{pH}$ of 7.5 to 4.5 during fermentation, which has clearly indicated that acidic conditions were developed due to the production of extracellular enzyme secretion by the cells that ultimately favoured the dextran production.

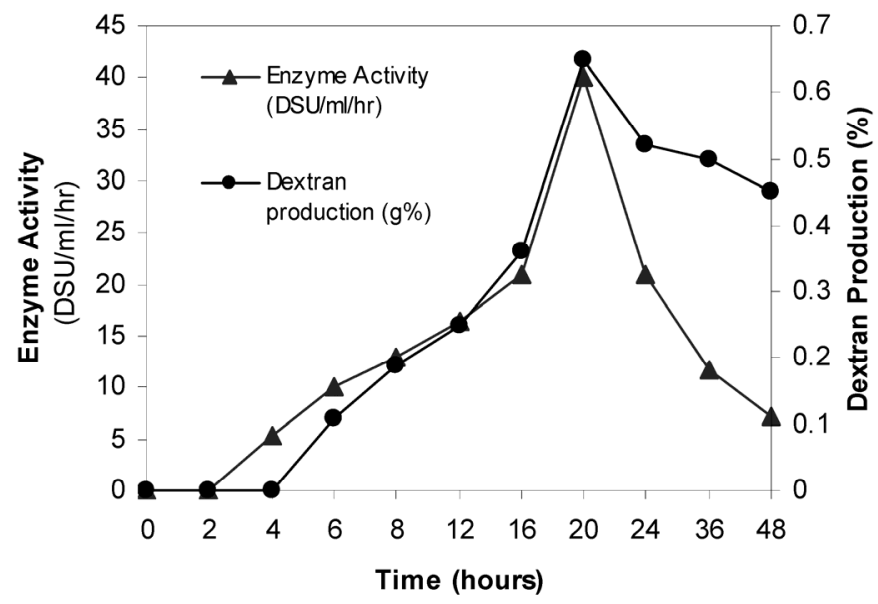

Figure 2: Time Course for Dextran and Dextransucrase Production by Leuconostoc mesenteroides CMG713 using 2\% sucrose medium. ( $\boldsymbol{\Delta}$ ) Maximum dextransucrase production was found in $20 \mathrm{hrs}$ incubation and sharp decline in production was observed in $24 \mathrm{hrs}$. (•) Dextran production was found maximum in $20 \mathrm{hrs}$ and than declined upto $48 \mathrm{hrs}$.

Table 1: Time Course of cellular growth, enzyme activity, $\mathrm{pH}$ and dextran production by L. mesenteroides CMG713 using 2\% sucrose in fermentation medium.

\begin{tabular}{|c|c|c|c|c|}
\hline $\begin{array}{l}\text { Incubation } \\
\text { time } \\
\text { (Hour) }\end{array}$ & Final pH & $\begin{array}{l}\text { Wet cell } \\
\text { mass } \\
(\mathrm{g} / \mathrm{dl})\end{array}$ & $\begin{array}{l}\text { Enzyme activ- } \\
\text { ity } \\
\text { (DSU/ml/hr) }\end{array}$ & $\begin{array}{l}\text { Dextran } \\
\text { production } \\
\text { (purified) } \\
\left(g^{0} \%\right)\end{array}$ \\
\hline 0 & 7.50 & 0.21 & - & - \\
\hline 2 & 7.15 & 0.29 & - & - \\
\hline 4 & 6.93 & 0.38 & 5.4 & - \\
\hline 6 & 6.64 & 0.61 & 10.0 & 0.11 \\
\hline 8 & 6.03 & 0.89 & 13.0 & 0.19 \\
\hline 12 & 5.33 & 1.36 & 16.5 & 0.28 \\
\hline 16 & 4.90 & 1.62 & 20.9 & 0.36 \\
\hline 20 & 4.77 & 2.40 & 30.0 & 0.65 \\
\hline 24 & 4.52 & 2.31 & 21.7 & 0.52 \\
\hline 36 & 4.50 & 2.11 & 11.8 & 0.50 \\
\hline 48 & 4.50 & 1.32 & 7.2 & 0.45 \\
\hline
\end{tabular}




\section{Effect of substrate concentration on dextran pro- duction}

The effect of different concentration of sucrose was studied in the range from $5 \%$ to $25 \%$. It was also observed that dextran production was effected by the different concentration of sucrose in the fermentation medium (Fig. 3). Maximum dextran yield was obtained when $20 \%$ sucrose concentration was used in the fermentation medium but there was a decrease in percent conversion of sucrose to dextran, which ultimately affected the yield. Perhaps higher concentration of sucrose in the fermentation medium had an inhibitory effect, known as substrate inhibitory effect, which decreased dextran production [28]. Similar observations were also reported by Kim et al. [29]. They studied the effects of sucrose concentration, $\mathrm{pH}$ and temperature on the yield of dextran by a mutant strain of L. mesenteroides B512 FMCM. Increasing sucrose concentration $(0.5-5.0 \%)$ supported increase in the yield of the dextran [30]. Detailed studies on the effects of high sucrose concentration have revealed that greater yields of high molecular weight dextran were obtained at high sucrose concentrations [31, 32]. In another study maltose was used as an acceptor molecule to study its effect on dextran yield and it was found that intermediate oligosaccharides were formed that ultimately decreased dextran yield [33]. Besides sucrose carob pod extract, cheese whey, molasses and wheat bran extracts have also been used as carbon source in the fermentation media for the production of dextran $[34,35]$.

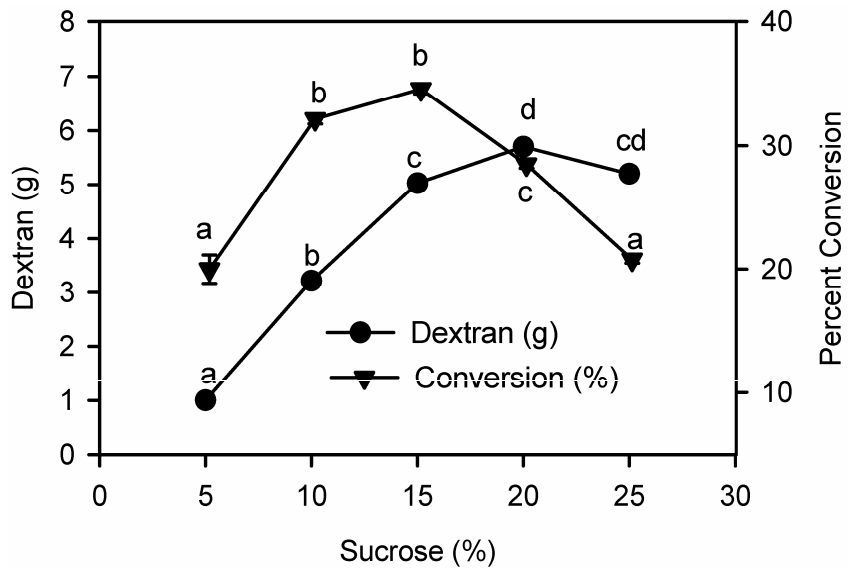

Figure 3: Effect of Substrate (sucrose) on Dextran production by Leuconostoc mesenteroides CMG713. Symbols (means \pm S.E., $\mathrm{n}=6$ ) having similar letters are not significantly different from each other (Bonferroni test, $\mathrm{P}<0.05$ ).

\section{Effect of temperature on Dextran Production}

Dextran production was determined at different temperature from $20^{\circ} \mathrm{C}$ to $45^{\circ} \mathrm{C}$ and the maximum dextran production by L. mesenteroides CMG713 was achieved at $30^{\circ} \mathrm{C}$. As the temperature increased a decreased in dextran production was noticed (Fig. 4). It has been reported earlier that temperature influenced the yield, rate of formation as well as molecular mass distribution of dextran. It had also been reported earlier that at temperature below the maxima, dextran produced was of low molecular mass [31,36]. Hehre \& Sugg [30] found that the yield of the dextran was considerably less at higher temperature $\left(35^{\circ} \mathrm{C}\right)$ as compared to the dextran production at $23^{\circ} \mathrm{C}$. This was due to the instability of the enzyme in the fermentation broth [30,37]. Similar observations were recorded in case of L. mesenteroides CMG713. When the incubation temperature was high, the temperature did not favor cell multiplication, and lead towards less enzyme and dextran production as compared to optimum temperature i.e. $30^{\circ} \mathrm{C}$.

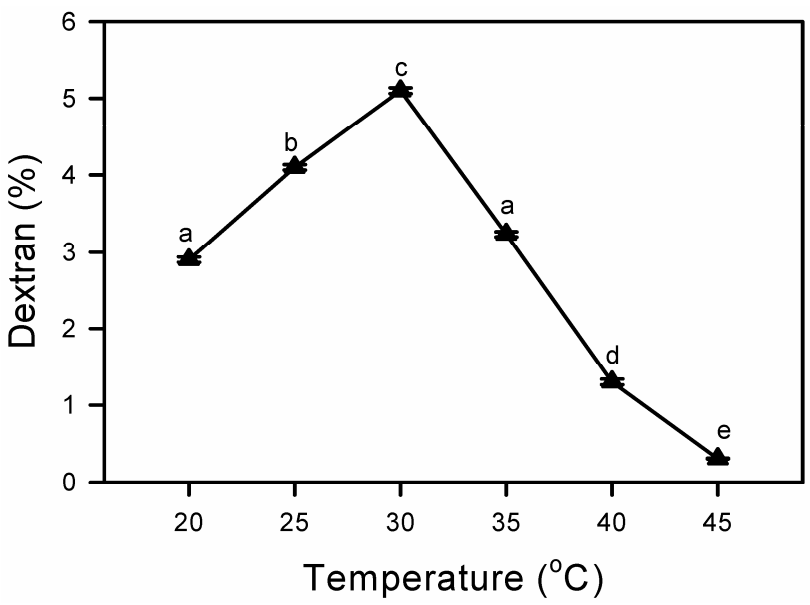

Figure 4: Effect of temperature on Dextran production at different incubation temperatures by Leuconostoc mesenteroides CMG713. Symbols (means \pm S.E., $n=6$ ) having similar letters are not significantly different from each other (Bonferroni test, $\mathrm{P}$ $<0.05)$.

\section{Effect of pH on Dextran Production}

Dextran production by L. mesenteroides CMG713 was also observed between $\mathrm{pH} 6.0$ to 8.0. Effect of $\mathrm{pH}$ on dextran production is shown in (Fig. 5), which indicates that when the $\mathrm{pH}$ of the initial fermentation medium was kept 7.0 before sterilization, maximum dextran production was achieved. At either extreme $\mathrm{pH}$ values of the optimum $\mathrm{pH}$ the dextran production was almost half as compared to optimum $\mathrm{pH}$. Santos et al. [38] have studied the effect of $\mathrm{pH}$ on dextransucrase activity and dextran production by L. mesenteroides NRRL B512F and found that maximum production was obtained at $\mathrm{pH}$ 5.5. 


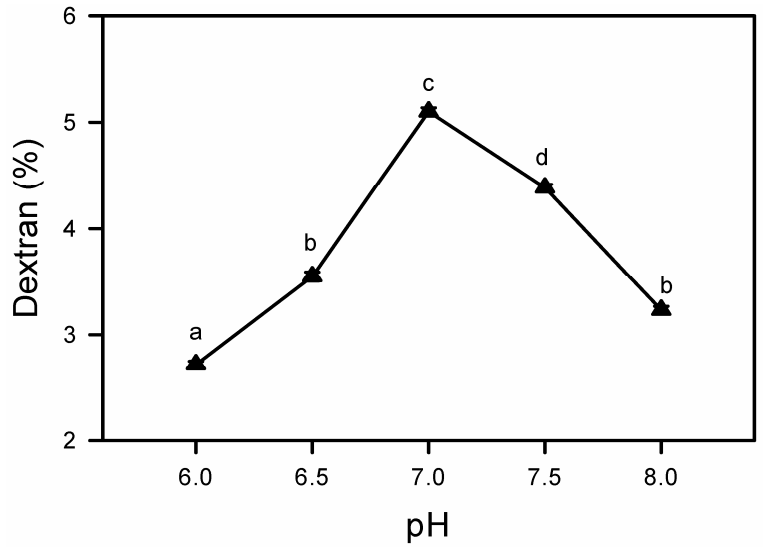

Figure 5: Effect of medium $\mathrm{pH}$ on dextran production by Leuconostoc mesenteroides CMG713. Symbols (means \pm S.E., $\mathrm{n}=$ 6 ) having similar letters are not significantly different from each other (Bonferroni test, $\mathrm{P}<0.05$ ).

\section{Characterization of Dextran}

Molecular mass distribution and viscosity of dextran

The results have suggested that dextran produced by CMG713 is of very high molecular weight. Molecular mass distribution of the dextran produced by L. mesenteroides CMG713 with reference to blue dextran and industrial grade dextran was estimated. Dextran from L. mesenteroides CMG713 was eluted earlier than blue dextran and was near to the industrial grade dextran indicating that its molecular mass distribution is approximately 2 million Da (Fig. 6) and nearly close to industrial grade dextran. Previously maltose along with sucrose was used to study its effect on dextran molecular weight and they concluded that maltose had no significant effect on its molecular weight [33]. High molecular weight dextran ( $\mathrm{Mw}>$ $1,000 \mathrm{kDa}$ ) was yielded when sucrose was used as a substrate during fermentation along with oligodextrans $(\mathrm{Mw}<10 \mathrm{kDa})$ [33]. High molecular weight dextran produced by L. mesenteroides CMG713 could be used in different biotechnological industries as well as it can be hydrolyzed in to different molecular weight fractions according to the need of various industries. Dextran in the molecular weight range from 12 to 98 $\mathrm{kDa}$ has important clinical uses and can be obtained by hydrolysis of high molecular weight dextran such as dextran produced by L. mesenteroides CMG713. Dextran obtained by CMG713 is of viscosity $14.58 \mathrm{cp}$. High viscosity of dextran has suggested that it has long chain of a $(1 \rightarrow 6)$ linkage in the main chain. a $(1 \rightarrow 6)$ linked polysaccharides, this represents a class of very flexible and extended polymer. The average molecular weight of native dextran produced by L. mesenteroides NRRL B512F had been investigated and the values for average molecular weight were determined in the range of $9 \times 10^{6}$ to $500 \times 10^{6} \mathrm{Da}$ [39-42]. Evidence of the presence of long branches had also been adduced from the studies on the molecular weight and viscosity during the biosynthesis of dextran [40]. The relationships between the molecular weight and the intrinsic viscosity $[\eta]$ had been investigated over a wide range of molecular weight [43-45]. Hibbert et al. [46] have also detected differences in physical and chemical properties of dextran produced by L. mesenteroides.

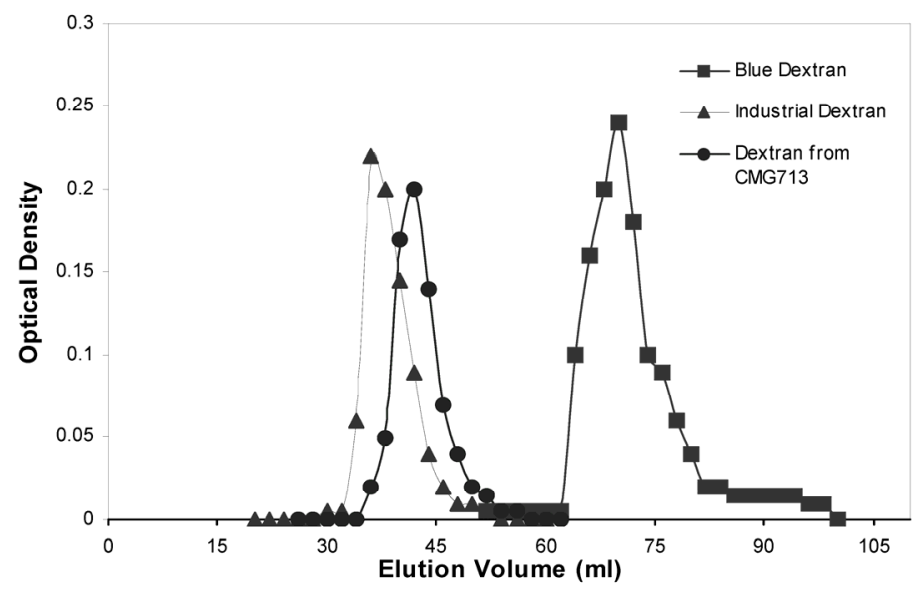

Figure 6: Molecular Mass Distribution of Dextran from Leuconostoc mesenteroides CMG713: Average molecular weight: Blue Dextran, 2000,000; Industrial dextran, 5000,000-40,000,000; Dextran from Leuconostoc mesenteroides CMG713, 5,000,000-20,000,000.

\section{Physico-Chemical Properties of Dextran}

Comparison of physical and chemical properties of dextran produced by Leuconostoc mesenteroides CMG713 with that of L. mesenteroides NRRL B512F is presented in Table 2. Dextran produced by L. mesenteroides CMG713 was amorphous and colourless. However, different dextrans produced by variants of L. mesenteroides produced range from gelatinous mass to granular precipitates [30]. These physical variations may be due to differences in molecular aggregation. Dextran produced by L. mesenteroides CMG713 was soluble in water giving a homogenous mixture of $5 \%$ solution, which was used for the analysis of the physical and chemical properties. Similar results have been reported for dextran produced by L. mesenteroides NRRL B512F that was also freely soluble in water, methyl sulfoxide, formamide, ethylene glycol and glycerol $[40,47]$. 
Table 2: Comparison of Physico-chemical Properties of Dextran produced by Leuconostoc mesenteroides CMG713 and reference strain of Leuconostoc mesenteroides NRRL B512F.

\begin{tabular}{|c|c|c|}
\hline Characteristics & $\begin{array}{l}\text { Leuconostoc mes- } \\
\text { enteroides CMG713 }\end{array}$ & $\begin{array}{l}\text { Leuconostoc mes- } \\
\text { enteroides } \\
\text { NRRL B512F }\end{array}$ \\
\hline Color\& Texture & $\begin{array}{l}\text { White, amorphous } \\
\text { powder }\end{array}$ & Colorless-light \\
\hline $\mathrm{pH}$ & 6.3 & $5.0-7.0$ \\
\hline Ash Content (\%) & 9.09 & 0.056 \\
\hline Moisture (\%) & 10.2 & - \\
\hline Viscosity & $14.58 \mathrm{cp}$ & $2.5-3.5$ \\
\hline $\begin{array}{l}\text { Average Molecular } \\
\text { Weight }\end{array}$ & $5,000-20,000 \mathrm{kDa}$ & $9,00-50,000 \mathrm{kDa}$ \\
\hline $\begin{array}{l}\text { Total Carbohydrate } \\
(\%)\end{array}$ & 79 & - \\
\hline Total Protein (\%) & 1.9 & 1.0 \\
\hline Reducing Sugar (\%) & 1.0 & 25 \\
\hline Linkages & a $(1 \rightarrow 6)$ linkage only & $\begin{array}{l}\text { a }(1 \rightarrow 6) \text { linkage with } \\
\text { a }(1 \rightarrow 4) \text { branched } \\
\text { linkage }\end{array}$ \\
\hline
\end{tabular}

\section{${ }^{13} \mathrm{C}-\mathrm{NMR}$ spectrometry of Dextran}

The ${ }^{13} \mathrm{C}$ and ${ }^{1} \mathrm{H}-\mathrm{NMR}$ spectra afforded the compelling evidence for the main structural features of dextran. The ${ }^{13} \mathrm{C}-\mathrm{NMR}$ spectra of dextran synthesized by dextransucrase from $L$. mesenteroides CMG713 is shown in Fig.7 (B). ${ }^{13}$ C-NMR spectrum of dextran from L. mesenteroides CMG713 displayed all the characteristic chemical shifts for a-glucose moiety and revealed that dextran showed the characteristics of predomi- nantly a $(1 \rightarrow 6)$ linkage in the main chain. The various signals in the NMR spectra were assigned as described earlier $[25,26]$. The structure of the synthesized polymer is comparable to that of dextran NRRL 512(F), except that there were no signals corresponding to any other linkage except a $(1 \rightarrow 6)$. The downfield shift of C6 carbon signal of glucose unit at $\delta 68.5$ clearly indicates that the two units of glucose in the polymeric chain have a $(1 \rightarrow 6)$ linkage. The chemical shifts of other carbons appeared as normal. The a $(1 \rightarrow 6)$ linkage of the polymeric chain was further cross checked by Heteronuclear Multiple Bond Connectivity (HMBC) interactions, shown in figure $7(\mathrm{~A})$. The anomeric proton H-1 ( $\delta$ 4.83) showed interactions with the neighbouring carbon $C-2(\delta 73.0)$ of the same sugar moiety and with the methylenic carbon C- $6(\delta$ 68.5) of the second sugar moiety, which proves the a $(1 \rightarrow 6)$ linkage. Further the H-6 protons $(\delta 3.75,3.60)$ also showed interaction with the neighbouring carbon C-5 $(\delta 76.3)$ and also with the anomeric carbon C-1 ( $\delta 100.6)$ of the other sugar moiety. On the basis of the above evidences it is proved that the linkage of the glucose units in the polymeric chain is almost $100 \%$ a $(1 \rightarrow 6)$ linkages among the two units, and there are no chances of any other branching like $(1 \rightarrow 3)$ linkage; as is present in the reported dextran produced by NRRL B512F $[48,49]$.
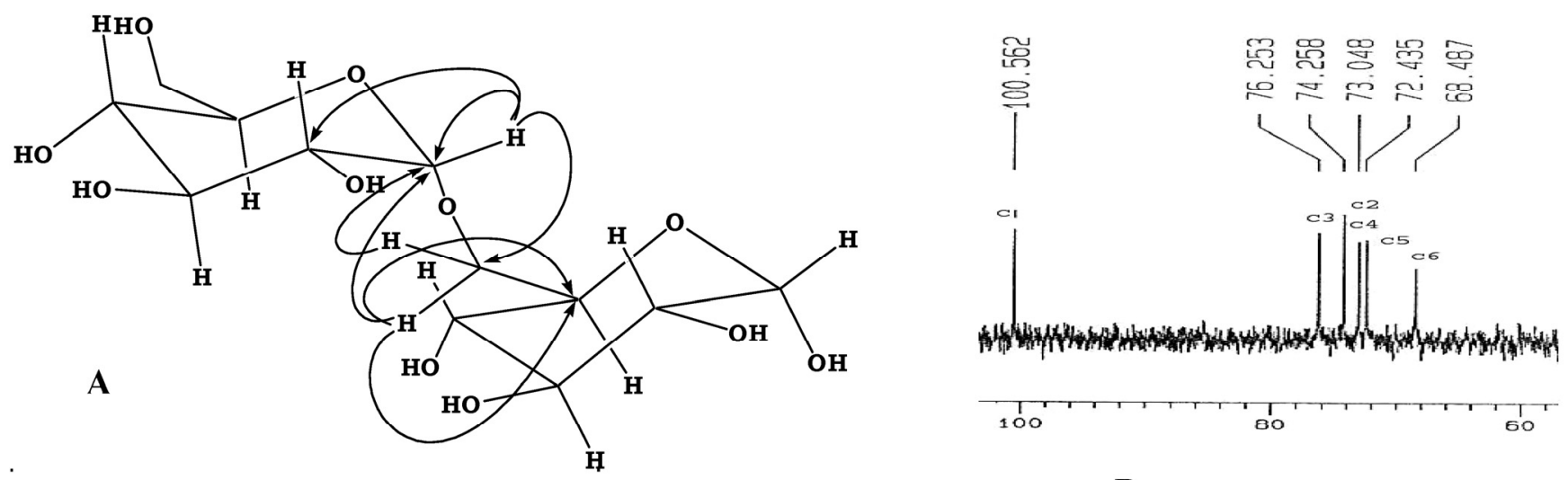

B

Figure 7: Key HMBC interactions showing ( $\alpha$ 1-6) linkage (A), and ${ }^{13}$ C-NMR analysis (B) of Dextran Synthesized by Dextransucrase from Leuconostoc mesenteroides CMG713.

\section{Acknowledgment}

We are very thankful to Dr. Muhammad Shaiq Ali and Dr. Liaqat Ali Malik of International Centre for Chemical and Biological Sciences for their help in interpretation of the ${ }^{13} \mathrm{C}-\mathrm{NMR}$ data. We are grateful to HEC for providing funds to use NMR facility at International Centre for Chemical and Biological Sciences.

\section{Abbreviations}

CMG: Centre for Molecular Genetics; DSU: Dextransucrase Unit; HMBC: Heteronuclear Multiple Bond Connectivity.

\section{Conflict of interest}

The authors have declared that no conflict of interest exists. 


\section{References}

1. Jeanes A. Dextran. In: Mark HF, Eds. Encyclopedia of polymer science and technology, Vol 4. New York: John Wiley and Sons Inc. 1966: 805-824

2. Sidebotham RL. Dextrans. Adv. Carbohydr. Chem. Biochem. 1974; 30:371-444

3. Monsan P, Bozonnet S, Albenne C, Joucla G, Willemot RM, Remaund-Simeon M. Homopolysaccharides from lactic acid bacteria. Int. Dairy J., 2001; 11:675-685.

4. Dols M, Remaud-Simeon M, Willemot R, Vignon M, Monsan P. Characterization of dextransucrase from Leuconostoc mesenteroides NRRL B-1299. Appl. Biochem. Biotechnol. 1997; 62: 47-59.

5. Goulas AK, Fisher DA, Grimble GK, et al. Synthesis of isomaltoligosaccharides and oilgodextrans by the combined use dextransucrase and dextranase. Enzyme Microb. Technol. 2004; 35: 327-338

6. Naessens M, Cerdobbel A, Soetaert W, Vandamme EJ. Leuconostoc dextransucrase and dextran: production, properties and applications. J. Chem. Technol. Biotechnol. 2005; 80: 845-860

7. Qader SA, Iqbal L, Aman A, Shireen E, Azhar A. Production of dextran by newly isolated strains of Leuconostoc mesenteroides PCSIR-3 and PCSIR-9. Turk J Biochem 2005; 31:21-26

8. Purama RK, Goyal A. Dextransucrase production by Leuconostoc mesenteroides. Ind. J. Microbiol. 2005; 2: 89-101

9. Purama RK, Goyal A. Identification, effective purification and functional characterization of dextransucrase from Leuconostoc mesenteroides NRRL B-640. Bioresource Technol. 2008; 99: 3635-3642

10. Santos VM. Estudo das condicoes de hidolise acida para obtencao de clinica, cominos. FEA-Uni CAMP 1996.

11. Pereira AM, Costa FAA, Rodrigues MI, Maugeri F. In vitro synthesis of oligosaccharides by acceptor reaction of dextransucrase from Leuconostoc mesenteroides. Biotechnol Lett. 1998; 20: 397-401

12. Santos M, Teixeira A, Rodrigues A. Production of dextransucrase, dextran and fructose from sucrose using Leuconostoc mesenteroides NRRL B512(f). Biochem. Eng. J. 2000; 4: 177-188

13. Holt JG. Group 17 Gram-Positive Cocci: Bergey's Manual of Determinative Bacteriology, ed $9^{\text {th }}$. Baltimore: William \& Wilkins. 1994: 529-541

14. Hamasaki Y, Ayaki M, Fuchu H, Sugiyama M, Morita H. Behaviour of psychrotrophic lactic acid bacteria isolated from spoiling cooked meat products. Appl. Environ. Microbiol. 2003; 69: 3668-3671

15. Qader SA, Iqbal L, Rizvi HA, Zuberi R. Production of dextran from sucrose by a newly isolated strain of Leuconostoc mesenteroides (PCSIR-3) with reference to Leuconostoc mesenteroides NRRL-B512F. Biotechnol Appl Biochem. 2001; 34: 93-97.

16. Jeanes A. Dextran. In: Whistler RL ed. Methods in Carbohydrate Chemistry Vol V. New York: Academic Press. 1965: 118-127

17. Shamala TR, Prasad MS. Preliminary studies on the production of High and Low viscosity dextran by Leuconostoc spp. Process Biochem. 1995; 30(3): 237-241

18. Kobayashi M, Matsuda K. The dextransucrase isoenzyme from $L$ mesenteroides NRRL B-512F. Biochimica Biophysics Acta 1974; 370: 441-449

19. Lopez A, Monsan P. Dextran synthesis by immobilized dextransucrase. Biochimie. 1980; 62:323-329

20. Lowry OH, Rosebrough NJ, Farr AL, Randall RJ. Protein measurement with the folin phenol reagent. J. Biol. Chem. 1951; 193: 265-275

21. Hassid WZ, Abraham S. Methods in Enzymology III. New York: Academic Press. 1957: 34-35

22. Nelson N. Photometric adaptation of the Somogyi method for the determination of glucose. J. Biol. Chem. 1944; 153: 375-380

23. Somogyi M. A new reagent for the determination of sugars. J. Biol. Chem. 1945; 160: 61-68
24. Dols M, Remaud-Simeon M, Willemot RM, Vignon M, Monsan $P$. Characterization of the different dextransucrase activities excreted in glucose, fructose, or sucrose medium by Leuconostoc mesenteroides NRRL B-1299. Appl Environ Microbiol. 1998; 64: 1298-1302

25. Seymour FR, Knapp RD, Bishop SH. Determination of the structure of dextran by ${ }^{13} \mathrm{C}$ nuclear magnetic resonance spectroscopy. Carbohydr Res. 1976; 51: 179-194

26. Remound M, Paul F, Monsan P, Lopez-Mungia A, Vignon R. Characterization of a $(1 \rightarrow 3)$ branched oligosaccharides synthesized by acceptor reaction with the extracellular glucosyltransferases from L. mesenteroides NRRL B-742. J Carbohydr Chem. 1992; 11: 359-378

27. Kullen MJ, Sanozky-Dewas RB, Crowell DC, Klaenhammer TR. Use of the DNA sequence of variable regions of the 16s rRNA gene for rapid and accurate identification of bacteria in the Lactobacillus acidophilus complex. J. Appl. Microbiol. 2000; 89: 511-516

28. Martinez-Espindola, JP, Lopez-Munguia CA. The kinetics of dextransucrase and dextran synthesis in batch reactors. Biotechnol Lett. 1985; 7: 483-486

29. Kim D, Robyt JF, Lee SY, Lee JH, Kim YM. Dextran molecular size and degree of branching as a function of sucrose concentration, $\mathrm{pH}$ and temperature of reaction of Leuconostoc mesenteroides B512FMCM dextransucrase. Carbohydr Res. 2003; 338: 1183-1189

30. Hehre EJ, Sugg JY. Serologically reactive polysaccharides produced through the action of bacterial enzymes: Dextran of Leuconostoc mesenteroides from sucrose. J Exp Med. 1942; 75:339-353

31. Tsuchiya HM, Hellman NN, Koepsell HJ, Carman J, Strainger CS, Rogovin SP, Bagard MO, Bryant G, Feger VH, Hoffnan CA, Senti FR, Jackson RW. Factors affecting molecular weight of enzymatic synthesized dextran. J Amer Chem Soc. 1955; 77: 2412-2419

32. Alsop RM. Progress in Industrial Microbiology, Vol 18. UK: Elsevier. 1983: 1-43

33. Rodrigues $\mathrm{S}$, Lona MF, Franco T. The effect of maltose on dextran yield and molecular weight distribution. Process Biosys Engr. 2005; 28: 9-14

34. Bahravan J, Bazzaz BS, Salimi Z. Optimisation of dextran production by Leuconostoc mesenteroides NRRL-B512 using cheap and local sources of carbohydrate and nitrogen. Biotechnol Appl Biochem. 2003; 38(Pt 3): 267-269

35. Santos M, Rodrigues A, Teixeira JA. Production of dextran and fructose from carob pod extract and cheese whey by Leuconostoc mesenteroides NRRL-B512 (f). Biochem Eng J. 2005; 25: 1-6

36. Ebert $\mathrm{KH}$, Brosche M. Origin of branches in native dextrans. Biopolymers 1967; 5(5): 423-429

37. Kaboli H, Reilly PJ. Immobilization and characterization of Leuconostoc mesenteroides dextransucrase. Biotechnol. Bioeng. 1980; 22(1):1055-1069

38. Santos M, Teixeira JA, Rodrigues A. Production of dextransucrase, dextran and fructose from sucrose using Leuconostoc mesenteroides NRRL-B512 (f). Biochem Eng J. 2000; 4(3):177-188

39. Hellman NN. Report on working conference on dextran. Peoria. 1951: 36

40. Bovey FA. Enzymatic polymerization: Molecular weight and branching during the formation of dextran. J Polymer Science 1959; 35:167-182

41. Elias HG. Pressure and concentration dependence of sedimentation coefficients. Makromol Chem. 1959; 29:30-47

42. Antonini E, Bellelli L, Bruzzesi MR, Caputo A, Chiancone E, Rossi-Ferrelli A. Properties of native dextran in different solvents. Biopolymers 1964; 2: 27-34

43. Granath KA. Solution properties of branched dextran. J Colloid Sci. $1958 ; 13: 308-328$ 
44. Gekko K, Noguchi H. Physicochemical studies of Oligodextran. I. Molecular weight dependence of intrinsic viscosity, partial specific compressibility and hydrated water. Biopolymers 1971; 10(9):1513-1524

45. Basedow AM, Ebert KH. Determination of molecular weight distributions and mean molecular-weight values of clinical dextrans. Infusionsther Klin Ernahr. 1975; 2(4):261-265

46. Hibbert H, Fowler FL, Buckland IK, Brauns F. Studies on reactions related to carbohydrates and polysaccharides: Structure of the dextran synthesized by the action of ;Leuconostoc mesenteroides on sucrose. Can. J. Res. 1937; 15: 486-497

47. Senti FR, Hellman NN, Ludwig NH, Babcock GE, Tobin R, Glass CA, Lamberts BL. Viscosity, sedimentation, and light-scattering properties of fraction of an acid-hydrolyzed dextran. J Polymer Science 1955; 17: 527-546

48. de Belder A. Dextran. Ullmans Encyclopaedia of Industrial Chemistry, 2002; : 25

49. Maina NH, Tenkanan M, Maaheimo H, et al. NMR spectroscopic analysis of exopolysaccharides produced by Leuconostoc citreum and Weissella confuse. Carbohy. Res. 2008; 343: 1446-1455 